\title{
GÊNERO, PATRIARCADO, TRABALHO E CLASSE $^{12}$
}

Helena Hirata ${ }^{3}$

\section{Resumo}

A conjunção das palavras-chave que compõem o título desse artigo remete imediatamente ao conjunto de reflexões e práticas do que se convencionou denominar "feminismo materialista" Assim, esse texto apresenta, de início, o feminismo materialista para, em seguida, abordar o tema do trabalho das mulheres e, mais geralmente, a relação entre trabalho e gênero, no contexto de um capitalismo patriarcal. Discute, enfim, o paradigma da interseccionalidade, que propõe a interdependência e a não-hierarquização das relações de poder de gênero, raça e classe social.

Palavras-chave: feminismo materialista; gênero e classe; interseccionalidade.

\begin{abstract}
Linking the key words present in the title of this article remind us immediately to all the ideas and practices of we call today "materialist feminism". Firstly, the article discusses the concept of materialist feminism. Secondly, it refers to the question of female labour and, more generally, to the relation between work and gender, in the context of patriarchal capitalism. Finally the article discusses the intersectional paradigm that states the interdependency and no-hierarchization of gender, race and class power relations.
\end{abstract}

Key-words: materialist feminism; gender and class; intersectionality.

\section{O feminismo materialista}

A conjunção das palavras-chave que compõem o título desse artigo remete imediatamente ao conjunto de reflexões e práticas do que se convencionou denominar "feminismo materialista".

O feminismo materialista se interessa pelas relações de poder, pelas relações de exploração, opressão, dominação entre homens e mulheres e é, ao

\footnotetext{
${ }^{1}$ DOI: https://doi.org/10.22409/tn.16i29.p4552

2Esse artigo resulta de uma comunicação ("Trabalho encomendado" pelo GT Trabalho e Educação) apresentada no dia 03/10/2017 durante a $38^{\circ}$ Reunião Nacional da ANPED em São Luis.

${ }^{3}$ Diretora de pesquisa emérita no Centre National de la Recherche Scientifique (CNRS), França e professora visitante internacional no Depto de Sociologia da USP.
} 
mesmo tempo, uma teoria e uma prática. Teorias feministas e movimentos feministas enquanto movimentos sociais são indissociáveis.

Para o feminismo materialista o trabalho é central em sua materialidade e enquanto prática social. A divisão sexual do trabalho profissional e do trabalho doméstico subjacente à divisão sexual do poder e do saber também é central para essa corrente do feminismo materialista. Ele critica a partir de uma perspectiva de gênero a teoria marxista das classes sociais (DELPHY, 1977; HIRATA E KERGOAT, 1994) porque ela não permite apreender o lugar das mulheres na produção e na reprodução social. Delphy (1977) mostrou como a classe social das mulheres é construída em referência exclusiva aos homens (marido, pai, etc) nos estudos de estratificação. Também Kergoat demonstrou em seus escritos como as relações de classe são sexuadas e as relações sociais de sexo são atravessadas por pontos de vista de classe - relações de sexo e relações de classe organizam, como diz Kergoat, a totalidade das práticas sociais. Não é so em casa que se é oprimida, nem só na fábrica que se é explorada.

Também é necessário se referir aqui à ideia do trabalho como "atividade paradigmática" (KERGOAT) isto é, afirmar a centralidade do trabalho contra os que preconizam o "fim do trabalho" (André Gorz, Jeremy Rifkin, Claus Offe, Dominique Méda, etc. ${ }^{3}$ No marxismo, as classes sempre foram tratadas como se o gênero não implicasse nenhuma heterogeneidade em sua composição (SOUZA LOBO, 2011 [1990], HIRATA e KERGOAT, 1994): "a classe operária tem dois sexos", como consta no título do livro póstumo de Elisabeth Souza Lobo e no artigo de Hirata e Kergoat.

As mulheres, no Capital, não têm existência enquanto sexo social, mas fazem parte, com outras categorias, do exército industrial de reserva (cf. crítica à categoria exército industrial de reserva, HIRATA, 2002). As atividades de trabalho estão sendo expulsas para a periferia do mundo capitalista. Bruno Lautier (1998) se refere aos cortadores de cana do Nordeste brasileiro.

Ao mesmo tempo assiste-se, sobretudo desde os anos cinquenta, ao desenvolvimento acelerado do setor de serviços e à conceitualização emergente de classes populares (Schwartz, 2011) para englobar o conjunto dos setores

\footnotetext{
${ }^{3}$ Para a apresentação da posição desses/as autores/as na controvérsia fim do trabalho $\mathrm{x}$ centralidade do trabalho, cf. Hirata, 1998.
}

TrabalhoNecessário- www.uff.br/revistatrabalhonecessario: ano 16, №29/2018 
assalariados proletarizados que não são abarcados pelo conceito de classe operária.

Enfim, é interessante o comentário de Alexis Cukier (2016), que mostra como Danièle Kergoat politiza o conceito de trabalho, junto com Christine Delphy e Silvia Federici. Segundo Cukier, essas autoras apontam para a "função política central do conceito de trabalho". A ideia de base dessas autoras seria, segundo ele, a indissociabilidade entre as funções econômicas (produção de bens e serviços) e politicas (reprodução e transformação das relações sociais), o que permite, segundo Cukier, "renovar a crítica marxista da economia politica" e pensar o trabalho como "alavanca da emancipação coletiva". Para esse autor, o feminismo materialista permite opor ao neoliberalismo a perspectiva de um trabalho feminista, pós-capitalista e democrático. A própria Danièle Kergoat afirma que é o "potencial crítico e subversivo dessa sociologia (crítica) que se trata de evidenciar (GALERAND, KERGOAT, 2014)". Ela dá preeminência às relações sociais e ao trabalho, no que se diferencia das sociologias das "diferenças entre os sexos" ou dos "gender studies", que não analisam conjuntamente trabalho e exploração, dominação e emancipação.

\section{O trabalho das mulheres no capitalismo patriarcal. Trabalho e gênero}

Apresentaremos a seguir, em traços amplos, a situação atual do trabalho das mulheres no quadro de um capitalismo patriarcal, entendendo por patriarcado "uma formação social em que os homens detêm o poder, ou ainda mais simplesmente o poder é dos homens". Ele é assim, quase sinônimo de "dominação masculina" ou de "opressão das mulheres" (DELPHY, 2009 [2000], p. 172). Para nós não existe uma formação social "patriarcado", separado do "capitalismo". Preferimos falar em capitalismo patriarcal. Ou, como bem formulou Danièle Kergoat, "Patriarcado e capitalismo se combinam e exploram dominando e dominam explorando" (KERGOAT, 1978, p. 44).

Se as mulheres sempre trabalharam, como mostram as historiadoras do trabalho feminino, a porcentagem de mulheres trabalhadoras passou, no caso da França, de um terço a metade no conjunto da população ativa em um século (MARUANI e MERON, 2012). No Brasil, considerando apenas a década passada, observa-se "um incremento de $24 \%$ na atividade feminina" (OLIVEIRA COSTA,

TrabalhoNecessário- www.uff.br/revistatrabalhonecessario: ano 16, №29/2018 
2013, p. 400). Portanto, uma convergência notável entre a França e o Brasil, no que diz respeito à divisão do trabalho profissional, é que a despeito da crise econômica mundial e da austeridade, a despeito da recessão econômica no Brasil, as mulheres se mantêm no mercado de trabalho e aumentam a sua participação.

Embora possamos constatar esse aumento nas taxas de atividade femininas, também se deve assinalar a persistência das desigualdades, tanto entre sexos, quanto entre raças e entre classes, na medida em que partimos do ponto de vista segundo o qual as relações sociais de gênero, de raça e de classe são interdependentes e indissociáveis.

Um indício de desigualdade está na segregação horizontal e vertical: as mulheres não têm acesso às mesmas profissões que os homens, estão limitadas a um número restrito de atividades, tanto na França quanto no Brasil e têm poucas perspectivas de promoção (o fenômeno do glass ceiling, o teto de vidro) e a polarização do emprego feminino. A segregação dos empregos e das atividades em todo o mundo é o que Danièle Kergoat (2012) chama o princípio da separação (distinção entre trabalho masculino e feminino).

Se as taxas de atividade aumentam, os empregos criados são vulneráveis e precários, com o desenvolvimento do trabalho informal no Sul. E, sobretudo, a coexistência da "expansão do mercado formal de trabalho" (CARNEIRO ARAUJO, LOMBARDI, 2013: p.473) com o informal absorvendo mais mulheres do que homens, mais negros do que brancos (idem, ib. 2013).

O desemprego feminino é maior do que o masculino na maioria dos países industrializados, e as mulheres são majoritárias no desemprego oculto pelo desalento (INSEE, Enquête Emploi, 2005.a). Na França, em 2012, a taxa de desemprego feminina é, em 2012, ligeiramente mais elevada (10\%) que a taxa de desemprego masculina $(9,7 \%)$, mas esse diferencial foi mais importante em todos os anos passados, chegando a ser de 4\% (em 1980 e em 1990); e de 3\% (em 2000).

Outra similitude entre a situação das mulheres ao nível internacional: elas têm sempre salários inferiores aos dos homens. Os salários femininos são inferiores aos salários masculinos, e há desigualdade salarial entre homens negros e brancos, mulheres negras e brancas. Segundo o INSEE, a desigualdade de salários entre mulheres e homens na França não tem variado nas últimas

TrabalhoNecessário- www.uff.br/revistatrabalhonecessario: ano 16, №29/2018 
décadas, o diferencial de salários permanecendo em torno dos 25\% (Silvera, 2014). Esse diferencial diminui no setor público e varia segundo as categorias sócio-profissionais. Assim, o diferencial mais significativo se observa entre os executivos, e o menor na categoria de empregados. Em 1950, o diferencial de salários era, como no Japão hoje, de $50 \%$ mas ele se estabilizou em torno de $25 \%$ desde a metade do século passado. No Brasil, o diferencial de salários está, hoje, em torno de $30 \%$ (OLIVEIRA COSTA, 2013), após um longo período em que esteve em torno de $35 \%$.

Quanto ao trabalho precário, sem proteção social e sem direitos, ele diz respeito a $30 \%$ das mulheres ocupadas, contra $8 \%$ dos homens ocupados (LOMBARDI, 2010). O exemplo paradigmático do trabalho precário é o emprego doméstico, sobretudo o emprego de diarista, majoritariamente exercido sem vínculo empregatício, sem proteção social e sem direitos. $16 \%$ das mulheres brasileiras ocupadas são empregadas domésticas.

Enfim, quanto à divisão sexual do trabalho doméstico: se indicamos desigualdades gritantes no que diz respeito ao trabalho profissional, pior ainda parecem ser as desigualdades no âmbito do trabalho doméstico: o que é atribuído a um e a outro sexo é um fator imediato de desigualdade e de discriminação. A atribuição do trabalho doméstico às mulheres permaneceu intacto em todas as regiões do mundo, com diferenças de grau na sua realização, dos modelos tradicionais aos modelos de delegação. A delegação às empregadas domésticas e diaristas é muito mais importante no Brasil do que na França, pois se há cerca de 1350000 mulheres trabalhando nos serviços domésticos e de cuidados na França (INSEE, Enquête Emploi, 2005.b), no Brasil, segundo o recenseamento da população de 2010, há 7000000 de pessoas no emprego doméstico, das quais cerca de $5 \%$ do sexo masculino.

Podemos concluir essa apresentação sumária das desigualdades entre mulheres e homens no trabalho, nos referindo à constatação feita sistematicamente hoje a partir das pesquisas empíricas em ciências sociais: a posição das mulheres e dos homens na hierarquia social, em termos de repartição do trabalho doméstico, de hierarquia profissional ou de representação politica não é a mesma nas sociedades contemporâneas. O paradoxo dessa desigualdade persiste, a despeito do fato de que as mulheres têm níveis de 
educação superiores aos dos homens em quase todos os níveis de escolaridade e em praticamente todos os países industrializados.

Por exemplo, na França, segundo os dados para 2012 da Pesquisa Emprego do INSEE, $87 \%$ de mulheres e $82 \%$ de homens, na faixa etária de 20-24 anos, possuem diplomas do ensino superior, do $2^{\circ}$ grau e equivalentes. Inversamente, entre os que não completaram os estudos e não obtiveram diplomas do $2^{\circ}$ grau, há mais homens $(18 \%)$ do que mulheres $(13 \%)$, segundo a mesma Pesquisa Emprego do INSEE. Na maioria das vezes, os desempenhos escolares das meninas são superiores aos dos meninos em escala mundial (Baudelot, Establet, 2013). Entretanto, a despeito do melhor desempenho escolar das mulheres em relação aos homens em quase todos os países industrializados, a situação de inferioridade das mulheres no mercado de trabalho permanece. $O$ que coloca uma série de questões sobre justiça e ética, conhecimento e ação politica, sobre os quais o paradigma interseccional tem avançado proposições que discutiremos a seguir.

\section{O paradigma interseccional}

Pode-se situar a gênese do paradigma interseccional nas elaborações teóricas do blackfeminism. Patricia Hill Collins (1990), Audre Lorde (1980), Angela Davis (1981), bell hooks (2015 [1982]), todas teóricas e militantes negras, afirmaram, desde 1981-1982, a natureza interseccional da opressão das mulheres negras (HILL COLLINS, 1990; cf. também Combahee River Collective, 1979). Mas é uma jurista negra, Kimberlé Crenshaw (1989a), que é conhecida como a teórica da interseccionalidade, a partir do seu objetivo de melhor formular os termos da ação jurídica para defender as mulheres negras contra a discriminação de raça e de sexo (e de classe). O que abarca o conceito de interseccionalidade?

A extensão desse conceito a outras categorias, como a sexualidade e a orientação sexual, a idade, a nação, a etnicidade, a deficiência, etc. faz parte central do debate (HIRATA, 2014). Creio que gênero contém a dimensão "sexualidade" e, portanto, a interseccionalidade deve apontar para a imbricação de gênero/sexualidade, raça e classe.

Embora a gênese do conceito de interseccionalidade possa ser situada, como dissemos acima, no final dos anos setenta, com o blackfeminism, cuja

TrabalhoNecessário- www.uff.br/revistatrabalhonecessario: ano 16, №29/2018 
crítica coletiva se voltou de maneira radical contra o feminismo branco, de classe média, heteronormativo, a vasta literatura existente em língua inglesa e mais recentemente também em francês aponta o uso, pela primeira vez desse termo para designar a interdependência das relações de poder de raça, sexo e classe, num texto da jurista afro-americana Kimberlé W. Crenshaw (1989.b).

A problemática da "interseccionalidade" foi desenvolvida nos países anglosaxões a partir dessa herança do blackfeminism, desde o início dos anos noventa, dentro de um quadro interdisciplinar, por Kimberlé Crenshaw e outras pesquisadoras inglesas, americanas, canadenses e alemãs. Entretanto, a ampla difusão e controvérsias em torno desse conceito na literatura feminista data da segunda metade dos anos 2000. Com a categoria da interseccionalidade Crenshaw (2005.a [1994]) focaliza, sobretudo, as interseções da raça e do gênero, abordando parcialmente ou perifericamente classe ou sexualidade, que podem contribuir para estruturar suas experiências (as das mulheres de cor) (CRENSHAW, 2005.b, p. 54).

A interseccionalidade é uma proposta para "levar em conta as múltiplas fontes da identidade" embora não tenha a pretensão de propor uma nova teoria globalizante da identidade (id. ibid.). Crenshaw propõe a subdivisão em duas categorias: a "interseccionalidade estrutural" (a posição das mulheres de cor na intersecção da raça e do gênero e as consequências sobre a experiência da violência conjugal e do estupro e das formas de resposta a tais formas de violência) e a "interseccionalidade política" (as políticas feministas e as políticas antirracistas que têm como consequência a marginalização da questão da violência em relação às mulheres de cor) (id. ibid). Essa formulação do início dos anos noventa, desenvolvida posteriormente pela própria Crenshaw e outras pesquisadoras, tem hoje, na definição de Sirma Bilge (2009), uma boa síntese:

\footnotetext{
A interseccionalidade remete a uma teoria transdisciplinar que visa apreender a complexidade das identidades $e$ das desigualdades sociais por intermédio de um enfoque integrado. (BILGE, 2009).
}

Ela refuta o enclausuramento e a hierarquização dos grandes eixos da diferenciação social que são as categorias de sexo/gênero, classe, raça, etnicidade, idade, deficiência e orientação sexual. O enfoque interseccional vai 
além do simples reconhecimento da multiplicidade, dos sistemas de opressão que opera a partir dessas categorias e postula sua interação na produção e a reprodução das desigualdades sociais (BILGE, 2009, p. 70).

É interessante notar que a problemática da "consubstancialidade" de Danièle Kergoat foi elaborada a partir do final dos anos setenta em termos de articulação entre sexo e classe social, para ser desenvolvida, mais tarde, em termos de imbricação entre classe, sexo e raça. Embora ambas partam da intersecção, ou da consubstancialidade, a intersecção, mais visada por Crenshaw no ponto de partida da sua conceptualização é aquela entre sexo e raça, enquanto a de Kergoat é aquela entre sexo e classe o que fatalmente terá implicações teóricas e políticas significativamente diferentes. Um ponto maior de convergência entre ambas é a proposta de não hierarquização dos tipos de opressão.

O desenvolvimento das pesquisas feministas na França, o contato com as ideias vindas de outro lado do Atlântico, as interpelações das feministas negras em países onde a opressão racial foi objeto de análise bem antes da França, como é o caso do Brasil, certamente contribuíram para uma sensibilização crescente às relações de poder ligadas à dimensão racial e às praticas racistas.

Embora pesquisadoras como Colette Guillaumin (1972, 1992) tivessem conceptualizado o racismo desde o início dos anos setenta e a "raça" desde os primeiros momentos da existência da revista Questions Féministes na França, no fim dos anos setenta, essa conceptualização não se fez em termos interseccionais ou de "co- extensividade" da raça, do sexo e da classe social.

O interesse teórico e epistemológico de articular sexo e raça, por exemplo, fica claro nos achados de pesquisas que não olham apenas para as diferenças entre homens e mulheres, mas as diferenças entre homens brancos e negros e mulheres brancas e negras, como fica claro nos trabalhos de Nadya Araujo Guimarães, no Brasil, mobilizando raça e gênero para explicar desigualdades salariais ou diferenças quanto ao desemprego (GUIMARÃES, 2002 e GUIMARÃES e ALVES DE BRITTO, 2008). A partir dos dados da PNAD 1989 e 1999, Araujo Guimarães mostra que, considerando sexo e raça, veem-se os homens brancos com os mais altos salários; em seguida, os homens negros e as mulheres brancas; e, por último, as mulheres negras com salários significativamente inferiores (GUIMARÃES, 2002, p.13).

TrabalhoNecessário- www.uff.br/revistatrabalhonecessario: ano 16, №29/2018 
Também considerando sexo e raça, a partir de levantamentos via Agência Nacional de Empregos (ANPE) 1995 e 1998, da França e via questionário suplementar à Pesquisa de Emprego e Desemprego (PED) da SEADE/DIEESE 1994 e 2001, Araujo Guimarães mostra que os imigrantes estrangeiros estão em formas mais precárias de emprego em relação aos franceses; que as mulheres negras e brancas na França estão mais representadas na inatividade, mas que há peso maior das mulheres negras em relação às brancas no desemprego e nas formas precárias de ocupação. No caso do Brasil, as mulheres brancas e negras têm trajetórias duradouras nas ocupações de menor prestígio e más condições de trabalho, como o emprego doméstico, as mulheres negras sendo mais numerosas nessas ocupações. Ambas estão também sobrerepresentadas no desemprego.

Homens brancos e negros estão sobrerepresentados nas trajetórias de emprego formal e de trabalho autônomo, embora os últimos em menor proporção. Eles têm trajetórias marcadas pela instabilidade de forma mais marcante que os homens brancos, indicando vulnerabilidade maior (GUIMARÃES, 2008, p. 51 e seg.).

O interesse jurídico de articular sexo e raça é cabalmente demonstrado por Crenshaw (2008) quando ela se refere ao caso de um contencioso jurídico na fábrica da General Motors nos Estados Unidos, que ilustra bem o que é interseccionalidade: o tribunal desagregou e recusou a acusação de discriminação racial e de gênero da parte de mulheres afro-americanas, afirmando que a GM recruta afro-americanos para trabalhar no chão de fábrica e que também recruta mulheres. O problema sublinhado por Crenshaw é que "os afro-americanos recrutados pela GM não eram mulheres e que as mulheres que a GM recrutava não eram negras. Assim, embora a GM recrutasse negros e mulheres, ela não recrutava mulheres negras" (CRENSHAW, 2008, p.91).

Enfim, o interesse político de articular sexo e raça como elementos indissociáveis para uma luta unitária tem sido demonstrado pelas teóricas da interseccionalidade e da consubstancialidade que situam a prática no prolongamento da teoria embora a questão do véu islâmico na França tenha, ao mesmo tempo, indicado as dificuldades dessa conjunção e o surgimento de controvérsias relacionadas à opressão de raça e à opressão de sexo.

A ideia de articular relações sociais de sexo e de classe foi proposta na França desde final dos anos setenta por Danièle Kergoat (1978), que quis

TrabalhoNecessário- www.uff.br/revistatrabalhonecessario: ano 16, №29/2018 
"compreender de maneira não mecânica as práticas sociais de homens e mulheres frente à divisão social do trabalho em sua tripla dimensão: de classe, de gênero e origem (Norte/Sul)" (KERGOAT, 2010, p. 93). A ideia de "genrer" a classe e "classer" o gênero foi desenvolvida ao longo da sua trajetória desde o artigo de 1978 e esteve na origem da criação de um laboratório, o Grupo de Estudos sobre a Divisão social e sexual do trabalho (GEDISST) no CNRS, consagrado aos eixos temáticos de gênero e trabalho na França, em 1983.

Propusemos (Hirata e Kergoat, 1984) um apanhado crítico sobre classe e gênero num artigo que retomava a herança teórica de Christine Delphy (1977) no seu texto clássico sobre as mulheres nos estudos sobre estratificação social e discutia as teses de Eric Olin Wright. Proposta similar foi feita no Brasil, também desde os anos oitenta, por Elisabeth Souza-Lobo (2011[1991]).

A crítica da categoria de interseccionalidade é feita explicitamente por Danièle Kergoat pela primeira vez em conferência no congresso da Associação Francesa de Sociologia (AFS) em Grenoble em 2006, publicada sob forma de artigo em 2009 e traduzido no Brasil em 2010. No artigo citado, ela critica a noção "geométrica" de intersecção. Segundo Kergoat:

Pensar em termos de cartografia nos leva a naturalizar as categorias analíticas (...) Dito de outra forma, a multiplicidade de categorias mascara as relações sociais. (..) As posições não são fixas; por estarem inseridas em relações dinâmicas, estão em perpétua evolução e renegociação. (KERGOAT, 2010, p. 98).

Essa crítica é aprofundada na introdução do seu recente livro, Se Battre, disent-elles (2012), pelos pontos seguintes: 1) a multiplicidade de pontos de entrada (casta, religião, região, etnia, nação, etc e não apenas raça, gênero, classe) leva a um risco de fragmentação das práticas sociais e à dissolução da violência das relações sociais com o risco de contribuir à sua reprodução; 2) não é certo que esses pontos remetem todos a relações sociais e talvez não seja o caso de colocá-los todos num mesmo plano; 3) os teóricos da interseccionalidade continuam a raciocinar em termos de categorias e não de relações sociais, privilegiando uma ou outra categoria, como por exemplo a nação, a classe, a religião, o sexo, a casta, etc, sem historicizá-los e por vezes não levando em conta as dimensões materiais da dominação (KERGOAT, 2012: 21-22). 
O ponto essencial, a meu ver, da crítica de Kergoat ao conceito de interseccionalidade é que ele não parte das relações sociais fundamentais (sexo, classe, raça) em toda sua complexidade e dinâmica. Entretanto, me parece que outra crítica, nem sempre explícita, é a de que a análise interseccional coloca em geral em jogo mais o par gênero-raça, deixando a dimensão classe social em um ângulo menos visível.

De uma maneira mais global, cremos que a controvérsia central quanto às categorias de interseccionalidade e consubstancialidade se refere ao que denominamos a "interseccionalidade de geometria variável". Assim, se para Danièle Kergoat existem três relações sociais fundamentais que se imbricam, e são transversais, o gênero, a classe e a raça, para outras (cf. a definição de Sirma Bilge, supra) a intersecção é de geometria variável, podendo incluir, além das relações sociais de gênero, de classe e de raça, outras relações sociais como a relação social de sexualidade, de idade, de religião, etc. Deve-se atentar, sobretudo no que se refere à metodologia de pesquisa, quais os elementos determinantes da intersecção que devem ser analisados na sua conjunção, atentando sempre à ideia de não hierarquização das relações de poder de gênero, de raça e de classe social, ideia desenvolvida e argumentada por teóricas supracitadas, como Danièle Kergoat e Patricia Hill Collins.

Essa ideia é, por exemplo, contrária à tese de uma sobredeterminação da classe sobre as outras dimensões da intersecção, pois o paradigma interseccional critica a ideia de uma determinação em última instância pela classe social. A tese da indissociabilidade entre gênero, raça e classe também vai contra uma análise unicamente a partir da categoria de gênero, pois tratar as relações de poder unicamente a partir de uma perspectiva de gênero pode reduzir a pertinência de tal análise apenas às mulheres brancas e burguesas.

Também é necessário enfatizar a tese segundo a qual a interseccionalidade pode ser vista como uma das formas de combate às opressões múltiplas e imbricadas e, portanto, como instrumento de luta politica. É nesse sentido que Patricia Hill Collins considera a interseccionalidade ao mesmo tempo como um "projeto de conhecimento" e uma "arma política". 


\section{Referências}

BILGE, Sirma. Théorisations féministes de l'intersectionnalité, Diogène, vol. 1, $\mathrm{n}^{\circ}$ 225, 2009, p. 70-88.

CARNEIRO ARAUJO, Ângela M, LOMBARDI, Maria Rosa. Trabalho informal, gênero e raça no Brasil do inicio do século XXI. In: Cadernos de Pesquisa, FCC, v. $43, n^{\circ} 149,2013$.

CRENSHAW, Kimberlé. W. "Demarginalizing the intersection of race and sex; a black feminist critique of discrimination doctrine, feminist theory and antiracist politics". University of Chicago Legal Forum, 1989, p. 139-167.

. Mapping the margins: intersectionality, identity politics

and violence against women of colo. In: ALBERTSON FINEMAN, M, MYKITIUK, R. (eds.) The public nature of private violence, New York, Routledge, 1994, p. 93118.

Beyond Entrenchment: Race, Gender and the New Frontiers of (Un)equal Protection. In: M. TSUJIMURA (ed) International Perspectives on Gender Equality \& Social Diversity, Sendai: Tohoku University Press, 2008.

CUKIER, Alexis. De la centralité politique du travail: les apports du féminisme matérialiste. In: BIDET, A., GALERAND, E., KERGOAT, D. (coord). Analyse critique et féminismes matérialistes, Cahiers du Genre, $\mathrm{n}^{\circ}$ hors-série, 2016, $\mathrm{p}$. 151-173.

DAVIS, Angela. Women, Race and Class. New York: Vintage Books, 1981.

DELPHY, Christine. Les femmes dans les études de stratification. In: MICHEL, Andrée (ed.) Femmes, sexisme et sociétés, Paris: PUF, 1977.

Par où attaquer le 'partage inégal ' du 'travail ménager' ? In: Nouvelles Questions Féministes, vol.22, n³ 3, 2003, p. 47-71.

Teorias do patriarcado. In: HIRATA, H., LABORIE, F., LE DOARÉ, H., SENOTIER, D. (coord) Dicionário crítico do feminismo, São Paulo: EDUNESP, 2009.

FASSA, Farinaz, LÉPINARD, Eléonore, ROCA I ESCODA, Marta (dir). L'Intersectionnalité : enjeux théoriques et politiques. Paris: La Dispute, coll. Le genre du monde, 2016.

FEDERICI, Silvia. Caliban et la Sorcière. Femmes, corps et accumulation primitive, Marseille/Genève-Paris: Senonevero/Entremonde, 2014..

GALERAND, Elsa, KERGOAT, Danièle. Les apports de la sociologie du genre à la critique du travail. In: La nouvelle revue du travail (revista on line), 4/2014. 
GUIMARÃES, Nadya Araujo \& BRITTO, Murillo Marschner Alves de. "Genre, race et trajectoires professionnelles. Une comparaison São Paulo et Paris". In: MARUANI, M., HIRATA, H. \& LOMBARDI, M. R. (orgs.). Travail et genre. Regards croisés. France Europe Amérique Latine. Paris, La découverte, pp. 46-60.

GUIMARÃES, Nadya Araujo. "Os desafios da equidade: reestruturação e desigualdades de gênero e raça no Brasil". Cadernos Pagu, n. 17-18, 2002, p. 237-266.

HILL, Collins, Patricia \& BILGE, Sirma. Intersectionality. Cambridge, Polity Press, Key Concepts Series. 2016.

HILL, Collins, Patricia (1990) Black Feminist Thought - Knowledge, Consciousness, and and The Politics of Empowerment. New York/London: Routledge, 2011.

HIRATA, Helena. Restructuration industrielle et division sexuelle du travail. Une perspective comparative, in revue Tiers Monde, $\mathrm{n}^{\circ} 154$, avril-juin 1998, p. 381402.

. Nova divisão sexual do trabalho? Um olhar voltado para a empresa e a sociedade. São Paulo: Boitempo, 2002.

. Gênero, classe e raça: interseccionalidade e consubstancialidade das relaçoes sociais, in Tempo Social, V.26, nº nov., 2014, p.61-74.

Revista Estudos Feministas, vol.2, $n^{\circ} 3$.

KERGOAT, Danièle (1994) A classe operaria tem dois sexos. In

HOOKS, Bell (2015[1982]) Ne suis-je pas une femme? Femmes noires et féminisme, Paris: Cambourakis, coll. Sorcières (Ain't I a Woman: Black Women and Feminism, Boston, South End Press, 1982).

KERGOAT, Danièle. Ouvriers=ouvrières. In: Critique de l'Economie Politique, $n^{\circ} 5$. Paris, 1978. Publicado também em Se battre, disent-elles, Paris, La Dispute, 2012).

. Dinâmicas e consubstancialidade das relações sociais. In Novos Estudos Cebrap, n. 86, 2010 [2009], p. 93-103.

. Se battre, disent-elles... Paris: La Dispute. 2012.

Lautier, Bruno. Introduction, in HIRATA, H., LAUTIER, B., SALAMA, P., Revue Tiers Monde, t. XXXIX, n 154, avril-juin 1998.

LOMBARDI, Maria Rosa. A persistência das desigualdades de gênero no mercado de trabalho, in Costa, Albertina et al (orgs.) Divisão sexual do trabalho, Estado e crise do capitalismo, Recife: SOS Corpo, 2010, p.33-56. 
LORDE, Audre. Age, Race, Class and Sex - Women Redefining Difference, Copeland Colloquium, Amherst College, April, 1980.

MARUANI, Margaret, MERON, Monique. Un siècle de travail des femmes en France 1901-2011, Paris : La Découverte, 2012.

OLIVEIRA COSTA, Albertina. Apresentação, Tema em destaque: "Trabalho e gênero", Cadernos de Pesquisa, Fundação Carlos Chagas, vol. 43, n. 149, maioagosto, 2013.

SCHWARTZ, Olivier. Peut-on parler des classes populaires ? In : La vie des idées.fr, 2011 (on line: http://www.laviedesidees.fr/Peut-on-parler-desclasses.html)

SILVERA, Rachel. Un quart en moins. Des femmes se battent pour en finir avec les inégalités de salaires. Paris: La Découverte, 2014.

SOUZA-LOBO, Elisabeth. A classe operária tem dois sexos: trabalho, dominação e resistência. São Paulo: Fundação Perseu Abramo, 1991.

Recebido em: 07 de fevereiro de 2018. Aprovado em: 26 de fevereiro de 2018.

Publicado em: 13 de junho de 2018. 